\title{
THE ATRIAL SOUND AND THE ATRIAL COMPONENT OF THE FIRST HEART SOUND
}

\author{
BY \\ PRISCILLA KINCAID-SMITH AND JOHN BARLOW \\ From the Department of Medicine, Postgraduate Medical School of London \\ Received October 4, 1958
}

In normal subjects inaudible presystolic vibrations can usually be demonstrated in a low frequency phonocardiogram. The relation of these vibrations to pathologically audible atrial sounds and the contribution of atrial action to the formation of the first heart sound are the subject of this paper. Several authors (Bramwell, 1935; Caeiro and Orias, 1937; Rappaport and Sprague, 1942; and Evans, 1943, 1954), have applied the term atrial component to describe the low-pitched initial vibration of the first sound seen on a phonocardiogram. These sound phenomena were originally attributed to atrial activity because they precede the summit of the $\mathrm{R}$ wave on a simultaneous electrocardiogram, and it was thought that ventricular components could not precede this event. Counihan et al. (1951), however, demonstrated low frequency vibrations preceding the peak of the $\mathrm{R}$ wave in a case of atrial fibrillation thus throwing some doubt on the atrial origin of the initial component of the first heart sound, and a recent publication (Reinhold and Rudhe, 1957), states that the atrium plays no part in the production of the first sound.

Methods. Low frequency apical phonocardiograms were obtained with an apparatus of which the frequency response specifications were those recommended for clinical work by Leatham (1952): his system of labelling is employed in the phonocardiograms (M.A. = mitral area. L.F. =low frequency). Because of possible variations in the onset of the QRS complex in different cardiographic leads, standard lead II was employed throughout. Confusion with summation sounds or third sounds is avoided in all phonocardiograms, by showing two cycles or a flat base line for at least $0.24 \mathrm{sec}$. preceding each atrial sound.

An atrial sound is defined as any audible vibration occurring after the $P$ wave, more than 0.23 sec. after the second sound and preceding the start of the QRS complex on a simultaneous cardiogram. Our definition of an atrial component of the first sound is clarified in the text.

Evidence will be presented in this paper to support the separation of the atrial phonocardiogram into two main components (Lewis, 1915; and Weitzman, 1955): (1) an inaudible early atrial vibration (I.A.V.), and (2) an audible atrial sound (A.S.). Later we shall discuss the relationship of these atrial vibrations to the atrial component of the first sound (A.C.F.).

\section{The Relation of Normal Atrial Vibrations to those found in Cardiovascular Disease AND CONDUCTION DisORDERS}

Early atrial vibrations, normally inaudible (I.A.V.), are seen in normal low frequency phonocardiograms. They occur $0.07-0.14 \mathrm{sec}$. after the beginning of the $\mathrm{P}$ wave (Fig. 1). In heart block the atrial phonocardiogram starts with low-pitched vibrations (I.A.V.) at thesame time interval after the P wave. The atrial vibrations in heart block may last as long as $0.14 \mathrm{sec}$., and they usually show final distinct waves of higher amplitude and frequency (A.S: Fig. 2). These two components (I.A.V. and A.S.) are best seen in complete heart block (Lewis, 1915) but they are also commonly seen in cases with a prolonged P-R interval. Weitzman (1955) demonstrated and measured the time relations of these two components of the atrial sound in hypertensive and ischæmic heart disease in the absence of prolongation of the $\mathrm{P}-\mathrm{R}$ interval. In these conditions as in heart block the timing of the first component (I.A.V.) corresponds to that of the inaudible 


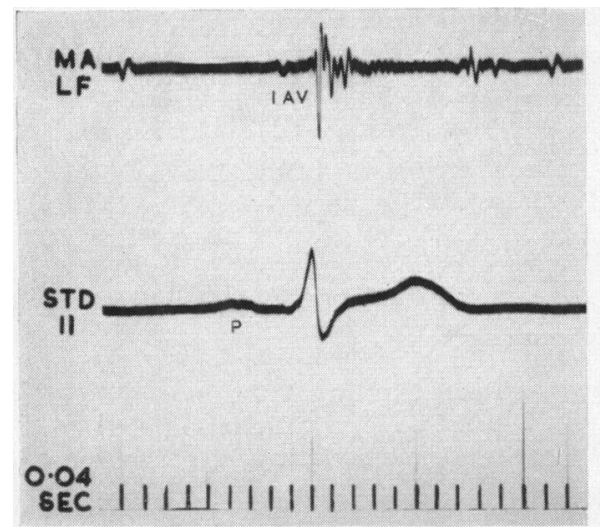

FIG. 1.-Phonocardiogram from a normal young man, showing the inaudible atrial vibration (I.A.V.) occurring $0 \cdot 12 \mathrm{sec}$. after the start of the $\mathbf{P}$ wave.

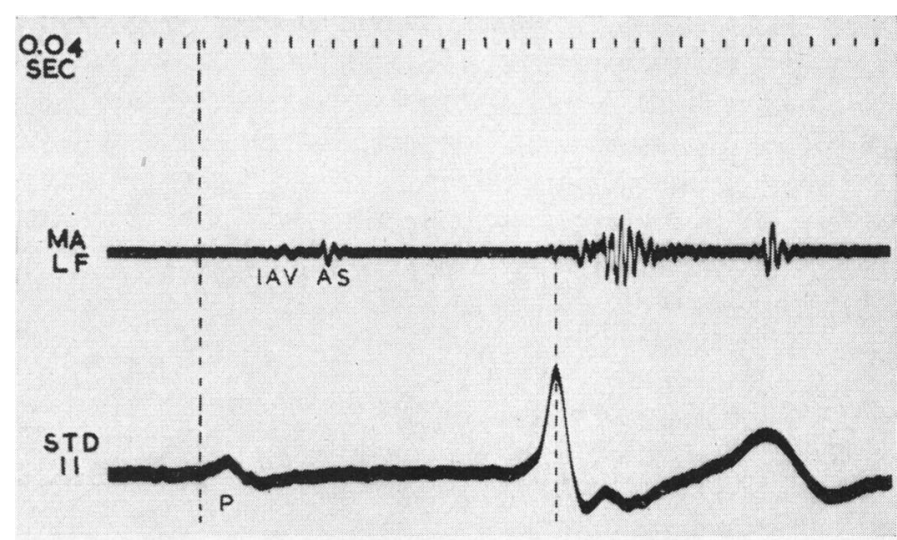

FIG. 2.-Phonocardiogram from a case of complete heart block, showing the two components of the atrial sound, the inaudible atrial vibration (I.A.V.) $0 \cdot 12 \mathrm{sec}$. after the $P$ wave and the atrial sound (A.S.) $0.24 \mathrm{sec}$. after the $P$ wave. The initial component of the ventricular phonocardiogram just precedes the peak of the $R$ wave.

presystolic vibrations in normal people: this vibration probably results from actual atrial contraction (Lewis, 1915; Weitzman, 1955). The second component of the atrial sound is probably the only component that is audible (Weitzman, 1955). It may appear with prolongation of the P-R interval beyond $0.20 \mathrm{sec}$. which allows the second atrial component $(0.20-0.28 \mathrm{sec}$. after the $P$ wave) to precede the first heart sound. A further observation that supports the separation of the atrial sound into these two components is the form of the atrial sounds that occur in the middle of ventricular systole in heart block. Fig. 3 shows that under these circumstances, where the atrium is contracting against closed $\mathrm{A}-\mathrm{V}$ valves, during ventricular systole, the first component is clearly recorded in the phonocardiogram whereas there is no sign of the second component, the base line being quite undisturbed at the time of its expected occurrence. This supports the

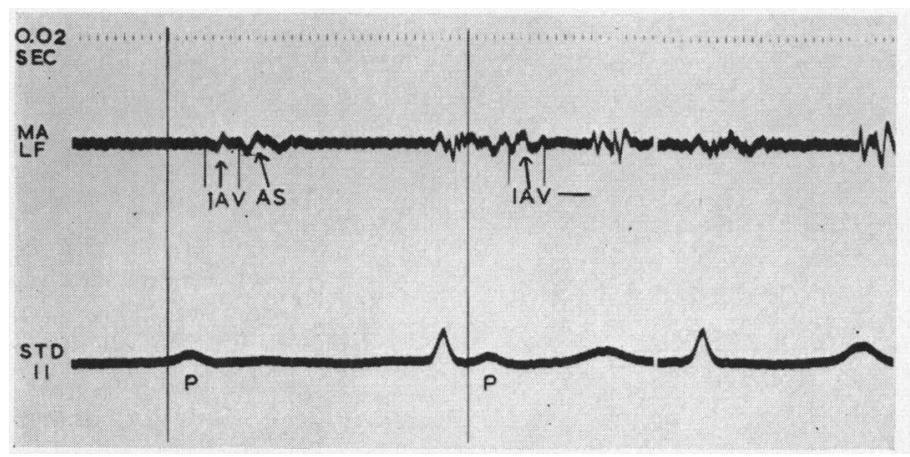

Fig. 3.-Phonocardiogram from a case of complete heart block, showing the two components of the atrial sound, I.A.V. and A.S. The second component (A.S.) does not occur when the atrioventricular valves are closed during ventricular systole.

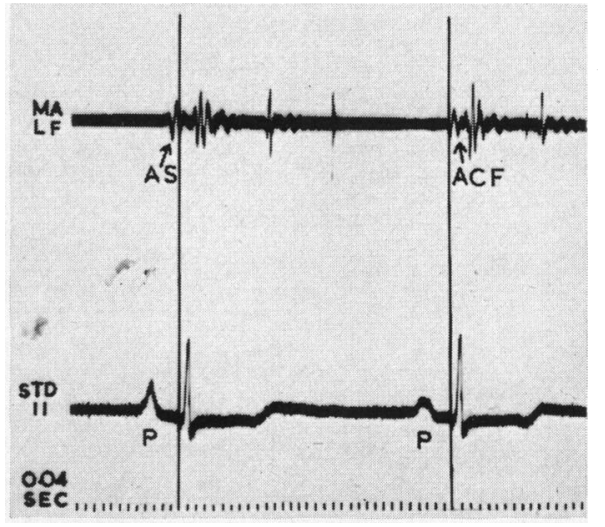

FIG. 4.-Phonocardiogram from a case of hypertensive heart disease, showing conversion of an atrial sound (A.S.) into an atrial component of the first sound (A.C.F.) resulting from carotid sinus pressure and change of $P$ wave shape without change in the $P-R$ interval. 
view that the first component is related directly to atrial contraction whereas ventricular filling is necessary for the occurrence of the second component.

Duchosal $(1932,1935)$ demonstrated that with clinical improvement in certain cardiovascular disorders, the atrial sound approaches and fuses with the first heart sound. With deterioration the atrial sound separates from the first heart sound becoming audible as a separate sound. This shift in timing, which may explain the audibility of the atrial sound (A.S.) where the P-R interval is normal, is the subject of another communication in which we support Duchosal's view (KincaidSmith and Barlow, 1959).

\section{The Effect of Carotid Sinus Pressure}

Read et al. (1955) reported the disappearance of a presystolic gallop as one accompaniment of slowing produced by carotid sinus pressure. Our phonocardiographic data in 140 cases of hypertension or ischæmic heart disease where carotid sinus pressure was applied are shown below. The actual sound was audible in all cases.

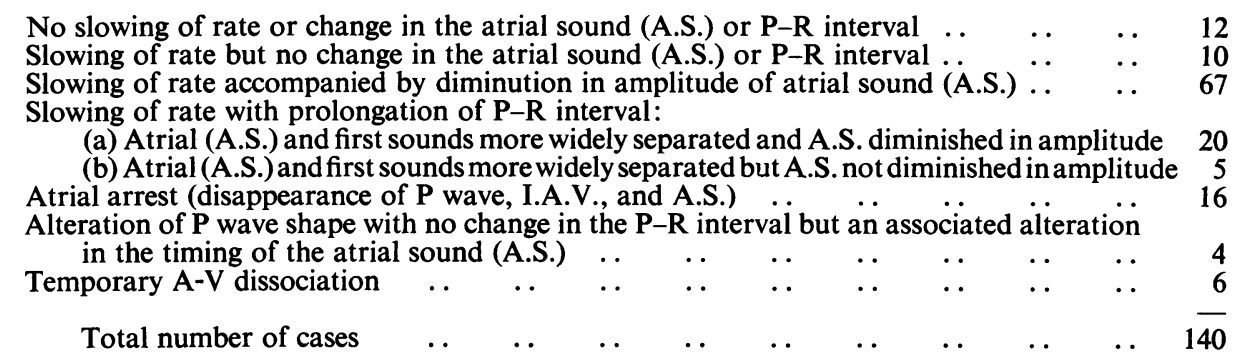

We were unable to record regularly two components of the atrial sound in ischæmic and hypertensive heart disease as reported by Weitzman (1955). This difference is likely to be due to a greater attenuation of low frequency elements in our recording system, thus eliminating the first atrial component in some records. Where recorded, the first component remained unchanged $0.07-0.14 \mathrm{sec}$. after the beginning of the $P$ wave.

In all but 22 instances carotid sinus pressure produced some change in the atrial sound. In almost half (67) a diminution in amplitude of the atrial sound occurred, and in a further 20 prolongation of the P-R interval was associated with diminution in amplitude of the vibration as well as a movement away from the first heart sound. The alteration in timing of the atrial sound was the same as the change in the P-R interval. In 16 cases atrial arrest resulted in the disappearance of the atrial sound (Fig. 5). All these findings substantiate the clinical observation that the atrial sound fades following carotid sinus pressure as occurred in 103 of these 140 patients. Occasionally, however, an atrial sound may become more easily audible with carotid sinus pressure due to wider separation from the first heart sound without significant decrease in intensity. An unexpected observation in four cases was the alteration in the timing of the atrial sound as a result of a change in $P$ wave shape without change in the P-R interval (Fig. 4).

\section{The Atrial Component of the First Heart Sound}

By applying these observations we have been able to establish the undoubted existence of an atrial component of the first heart sound. As stated above, with improvement in the clinical condition of patients with hypertension and ischæmic heart disease the audible atrial sound disappears. The mode of disappearance in all cases that we have studied, has been a movement towards and fusion with the first heart sound (Kincaid-Smith and Barlow, 1959). Where we have been able to record two components, the timing of only the second atrial component alters, the first component remaining in its usual position $0.07-0.14$ sec. after the $P$ wave. When the atrial sound fuses with the first sound, it is seen as a low frequency vibration (A.C.F.) between the start of the ventricular electrocardiogram and the first major component of the first sound (Fig. 4, 7, $8,9)$. It thus forms the initial component of the first heart sound and at this stage it may be indis- 

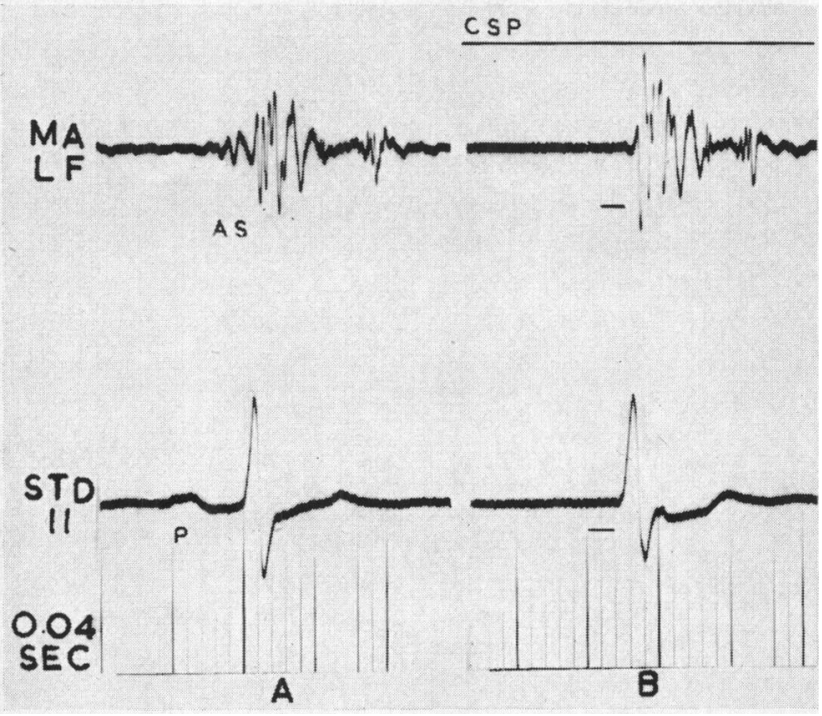

FIG. 5.-Phonocardiogram from a case of ischæmic heart disease, showing atrial arrest and disappearance of the atrial sound resulting from carotid sinus pressure.

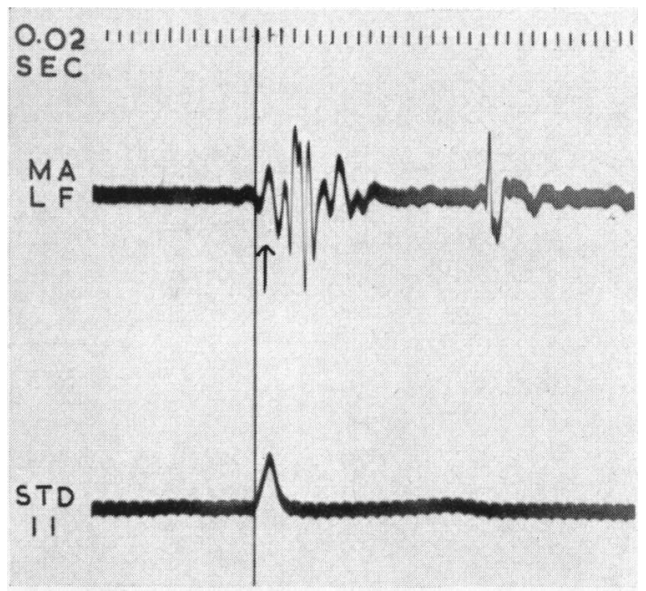

FIG. 6.-Phonocardiogram from a normal young man. The arrow indicates the initial low pitched vibration of the first sound which precedes the peak of the $R$ wave and resembles the atrial component of the first sound seen in cardiovascular disorder.

tinguishable on auscultation and phonocardiography from a similar vibration occupying this position in the normal first heart sound (Fig. 6). As we had watched the shift of the vibration from a presystolic position in the patients with cardiovascular disorders, we were satisfied that in these cases it was dependent on atrial activity.

In order to obtain more direct proof we studied the effect of carotid sinus pressure in 20 such cases in which the atrial vibration formed part of the first sound. The results were similar to those

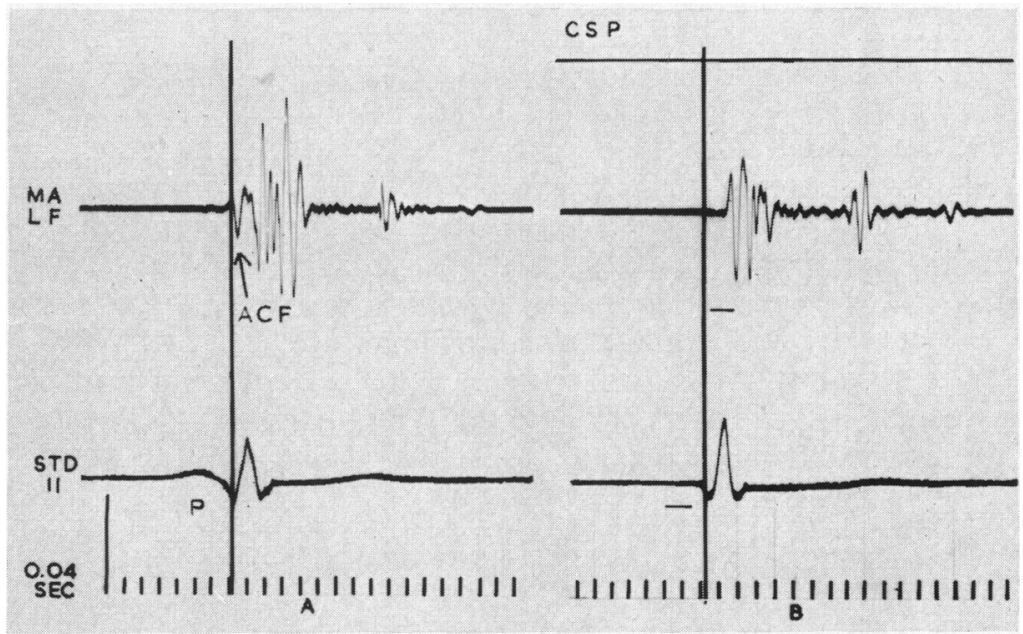

Fig. 7.-Phonocardiogram from a case of ischæmic heart disease, showing atrial asystole and the disappearance of the atrial component of the first sound as a result of carotid sinus pressure. 
already shown in the group with presystolic atrial sounds. The most striking and convincing change was the disappearance of the initial first sound component (A.C.F.), when atrial arrest resulted from carotid sinus pressure (Fig. 7). Where a prolongation of the P-R interval occurred, the atrial component of the first sound moved in the same direction and to the same extent as the $\mathbf{P}$ wave, thus converting an atrial component (A.C.F.) of the first sound into a presystolic atrial sound (A.S.) by altering the timing from just after the start of the ventricular electrocardiogram to just before the onset of Q (Fig. 8). An alteration in P wave shape may have an effect on the timing of the atrial sound, and may thus convert an atrial sound (A.S.) into an atrial component of the first sound (Fig. 4) or vice versa. Even where an alteration in timing was not seen, a decrease in amplitude or even a virtual disappearance of the initial component of the first sound almost invariably accompanied the carotid sinus slowing.

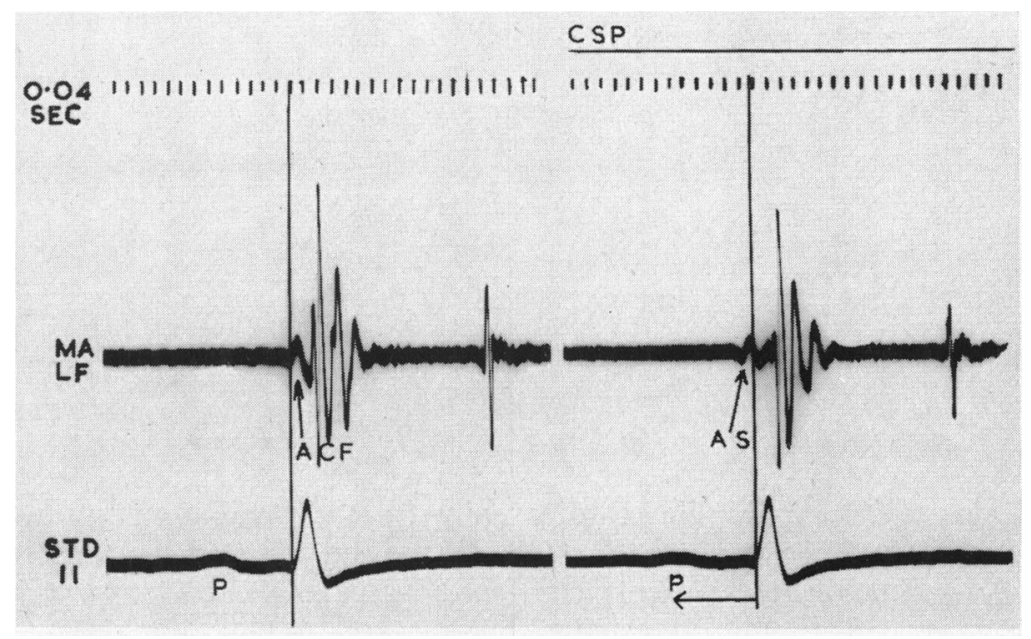

FIG. 8.-Phonocardiogram from a case of hypertension, showing prolongation of the P-R interval, and the conversion of an atrial component of the first sound into an atrial sound, resulting from carotid sinus pressure.

The auscultatory accompaniments of these phonocardiographic changes were similar to those described for the atrial sound-a fading of the initial low pitched component of the first heart sound. Thus a first sound that seemed to consist of two components, one of low pitch and the second high pitched, often became a single high pitched sound following carotid sinus pressure. Obvious splitting of the two major components of the first sound (mitral and tricuspid closure) sometimes only became apparent as two equal high pitched elements, when the low pitched initial (atrial) component faded in the few cycles following carotid sinus pressure.

The development of atrial fibrillation in two patients provided further evidence for the atrial origin of the initial component of the first sound. Both had ischæmic heart disease and serial records had shown the atrial sound approaching and merging into the first heart sound with clinical improvement. When fibrillation commenced, the initial (atrial) component of the first sound disappeared (Fig. 9).

\section{The Atrial Component of the First Heart Sound and its relation to the NoRmal SPLIT FIRST SOUND}

Splitting of the first heart sound is common in normal subjects (Leatham, 1954). In many the two elements of the split sound are of the same intensity and pitch, and probably result from 


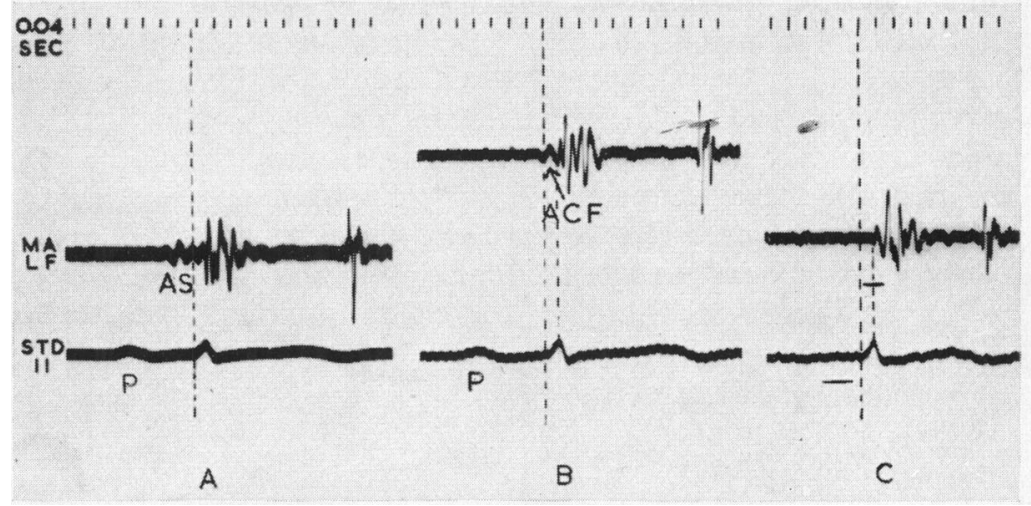

Fig. 9.-Phonocardiogram from a case of ischæmic heart disease. (A) was taken two days after an acute myocardial infarction. Serial records thereafter showed the atrial sound (A.S.) approaching and fusing with the first heart sound, thus becoming an atrial component of the first sound (A.C.F.) as seen in (B). (C) was taken during transient atrial fibrillation and shows the disappearance of A.C.F. during the arrhythmia.

asynchronous closure of the mitral and tricuspid valves (Reinhold and Rudhe, 1957). In a proportion, however, the first element of the split is loud and low-pitched and may be indistinguishable clinically and in the phonocardiogram from the atrial component of the first heart sound described above in ischæmic and hypertensive heart disease. Because of this resemblance it seemed reasonable to suppose that this low-pitched initial component in normal subjects was atrial in origin.

In fifteen normal young subjects in whom a low-pitched initial first sound component was heard, phonocardiograms showed that this sound vibration resembled the atrial component in patients with cardiovascular disorders. The vibration preceded the peak of $R$ in all instances and in one it began with $Q$ (Fig. 6). Unlike the group with proven atrial components of the first

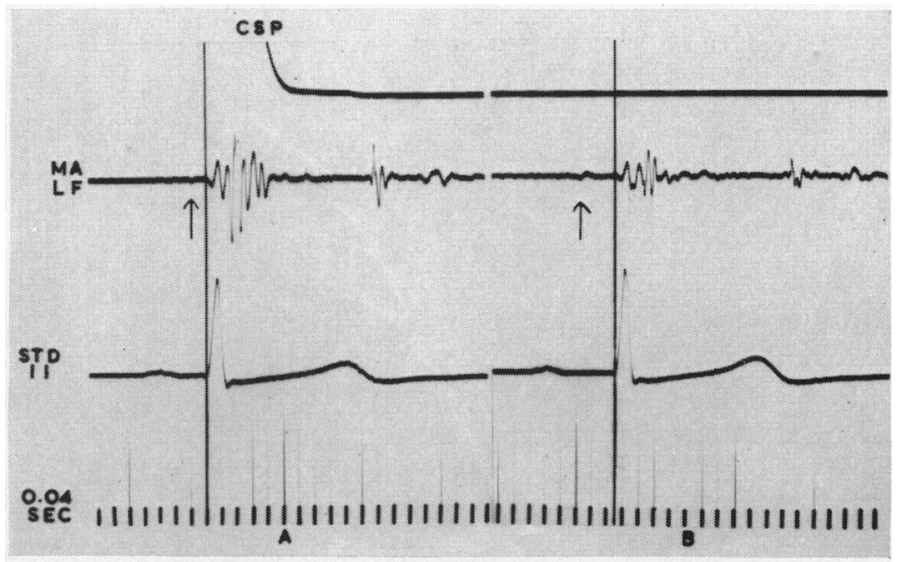

FIG. 10.-Phonocardiogram from a normal young man, showing an initial low-pitched component of the first sound which is not influenced in timing by prolonging the $\mathrm{P}-\mathrm{R}$ interval from 0.16 to $0.21 \mathrm{sec}$. by carotid sinus pressure Contrast with Fig. 8 which shows the movement of the atrial component of the first sound with the $P$ wave during this procedure in the case of hypertension. The inaudible atrial vibration (I.A.V.), indicated by the arrow, moves with the $P$ wave. 
sound, however, no clinical alteration in this split first sound accompanied carotid sinus pressure, even where marked slowing occurred. Carotid sinus pressure produced no change in the configuration of the first sound on the phonocardiogram such as occurs in the atrial component of the first sound in cardiovascular disease (cf. Fig. 7, 8). The only conduction defect that resulted from carotid sinus pressure in these normal subjects was a prolongation of the P-R interval in one case; this was achieved after sensitization of the carotid sinus by complete digitalization in one normal young man: in spite of alteration of timing of the $\mathrm{P}$ wave by $0.05 \mathrm{sec}$. (P-R prolonged from $0 \cdot 16-0 \cdot 21)$ there was no alteration in the timing or appearance of the initial first sound component (Fig. 10: contrast Fig. 8). This difference seemed to indicate that the initial first sound vibration in these normal subjects was not comparable to the atrial component of the first sound demonstrated in the group with abnormal hearts.

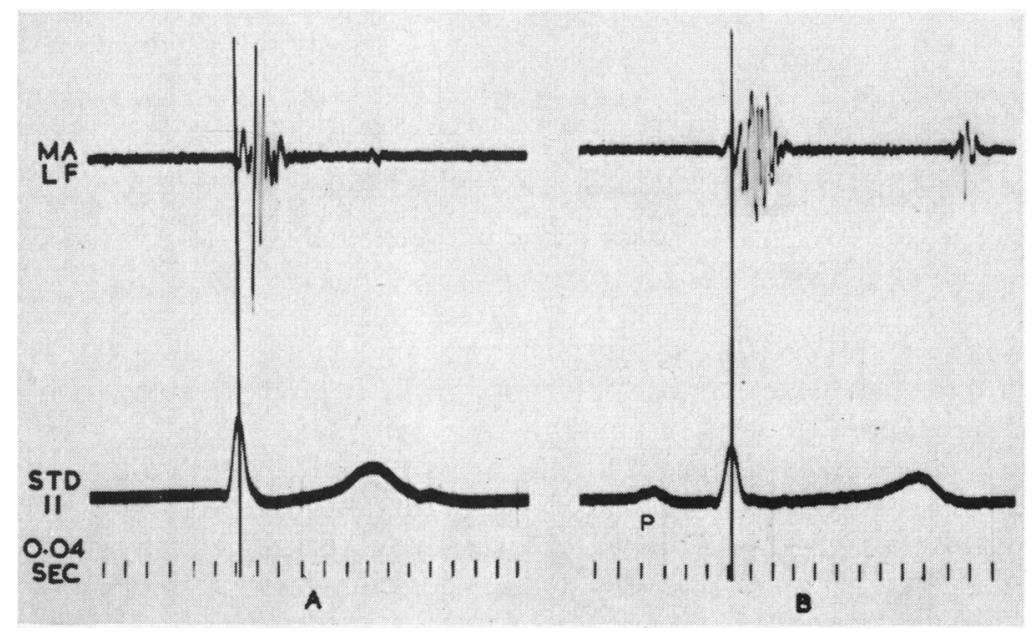

FIG. 11.-Phonocardiogram from a young woman with no detectable cardiac abnormality other than atrial arrest complicating a staphylococcal pneumonia. The first heart sound started constantly $0.02 \mathrm{sec}$. earlier in sinus rhythm (B) than during the arrhythmia (A).

Observations were made on the effect of atrial action on the first sound during temporary arrhythmia in two patients. In a young woman with atrial standstill complicating staphylococcal pneumonia, phonocardiograms in the absence of atrial activity failed to show any vibration preceding $R$, but such a vibration reappeared when the patient reverted to sinus rhythm (Fig. 11). Splitting of the first sound with a low pitched initial component could be heard after complete recovery, while no splitting of the first sound was audible in the absence of atrial action. Checked in numerous records in both sinus rhythm and during the arrhythmia, the vibration began $0.02 \mathrm{sec}$. earlier in sinus rhythm than in the absence of atrial activity. In a man aged 40 with lone paroxysmal atrial fibrillation, phonocardiographic tracings during fibrillation showed that vibrations began $0.02 \mathrm{sec}$. after the peak of the $R$ wave, whereas in sinus rhythm the initial first sound vibration constantly preceded $\mathrm{R}$ by $0.015 \mathrm{sec}$.

Thus atrial action may influence both the timing and the audibility of the initial first sound component in patients with rhythm disturbance and otherwise apparently normal hearts.

\section{Discussion}

We subscribe to the view that the atrial phonocardiogram has two components, the first inaudible (I.A.V.), the second the audible atrial sound (A.S.). These two components occur in hypertensive and ischæmic heart disease and in heart block, but only the first component (I.A.V.) 
appears in normal phonocardiograms. An atrial sound is never heard unless there is a defect of conduction or some impairment of cardiac function-most commonly with hypertensive and ischæmic heart disease, but also with cor pulmonale and anæmia and other cardiac abnormalities. As a rule the more severe the functional impairment the earlier the atrial sound occurs.

The participation of the atrium in the production of the initial components of the first heart sound, although widely accepted, has not hitherto been decisively demonstrated or disproved. The disappearance of the initial component of the first sound when atrial activity is arrested (Fig. 7) seems to provide conclusive evidence that it is dependent upon atrial action. We were only able to demonstrate an atrial component of the first heart sound conclusively in patients with cardiovascular disorders. In such cases the initial first sound vibration differs from the presystolic atrial sound only in its time relation to the start of the ventricular electrocardiogram, and this can be altered by prolonging the $\mathrm{P}-\mathrm{R}$ interval when the atrial vibration moves with the $\mathrm{P}$ wave (Fig. 8).

\section{The Atrial Component of the First Sound And the Split First Sound IN NoRMal SUBJECTS}

Dock (1933) concluded that the audible elements of the first heart sound were entirely valvular. Wolferth and Margolies (1935) and Leatham (1954) have stated that splitting of the first heart sound is due to asynchronous right and left ventricular events, but Evans $(1943,1954)$ accepts that it may also be due to separation of atrial and ventricular components.

We agree with Leatham (1954) that on careful auscultation in nearly all normal subjects the first sound is split to some degree. In those in which the duplication is due to asynchronous ventricular events we believe that the two components are of similar intensity and character, a feature that has been used to differentiate between a split first sound and an atrial sound (Lian, 1948; Leatham, 1954; and Weitzman, 1955). In our experience, however, about 5-10 per cent of normal subjects, particularly young men, have a low pitched first component of the first sound clinically indistinguishable from a late atrial sound in cardiovascular disorders. The fifteen normal subjects studied were selected from this group, and all their phonocardiograms showed that this low pitched audible sound preceded $\mathrm{R}$, thus being identical with the tracings from patients with cardiovascular disease who had atrial components of the first sound.

In spite of this phonocardiographic and clinical resemblance, the initial first sound vibration in normal subjects did not show the same response to carotid sinus pressure as the atrial component of the first sound in hypertensive and ischæmic heart disease. It did not change in intensity and could not be converted into an atrial sound by this method of prolonging the $\mathrm{P}-\mathrm{R}$ interval. In two patients with apparently normal hearts we were, however, able to show that atrial action influenced the time of onset of the "initial first sound vibrations" in that they occurred 0.02 to $0.03 \mathrm{sec}$. earlier in sinus rhythm than during atrial standstill or fibrillation.

These observations seem to indicate that even in the normal subject the atrium plays some part in the formation of the first heart sound. As it may contribute to both the timing and the audibility of the initial first sound vibration, there would be a case for calling this the atrial component of the first sound. It appears, however, to have a different mechanism from the undoubted atrial component of the first sound that we have demonstrated in cardiovascular disease, and as the latter seems to be identical with the atrial sound in all but timing, we prefer to distinguish between the two. We suggest therefore that simple descriptive term, "initial first sound vibration," suggested by Reinhold and Rudhe (1957) be retained to describe this phenomenon in normal subjects.

At the bedside carotid sinus pressure provides a useful method of distinguishing atrial sounds and atrial components of the first sound in patients with cardiovascular disorders, from split first sounds in normal subjects. The former almost invariably fades or disappears whereas the latter remains unchanged. Possible hypotheses based on these and other observations as to the 
mechanism and significance of the atrial sound are put forward elsewhere (Kincaid-Smith and Barlow, 1959).

\section{SUMmARY}

The atrial phonocardiogram can be separated into inaudible and audible components: only the inaudible component occurs in normal subjects.

Carotid sinus pressure usually diminishes the amplitude of the atrial sound.

An atrial component of the first sound can be conclusively demonstrated in certain cardiovascular disorders: it represents the same phenomenon as the audible atrial sound.

The relationship of this proved atrial component to the low pitched initial component of the normal first heart sound is discussed.

We are very grateful to Professor J. McMichael, F.R.S. for his help in the preparation of this paper.

\section{REFERENCES}

Bramwell, C. (1935). Quart. J. Med., 28, 139.

Caeiro, A., and Orias, O. (1937). Rev. Argent Cardiol., 4, 71 (quoted by Rappaport and Sprague, 1942).

Counihan, T., Messer, A. L., Rappaport, M. B., and Sprague, H. B. (1951). Circulation, 3, 730.

Dock, W. (1933). Arch. intern. Med., 51, 737.

Duchosal, P. (1932). Amer. Heart J., 7, 613.

(1935). Arch. Mal. Cour, 28, 345 .

Evans, W. (1943). Brit. Heart J., 5, 205.

(1954). Cardiography. Butterworth, London.

Kincaid-Smith, P., and Barlow, J. (1959). Brit. Heart J., 21, 479.

Leatham, A. (1952). Brit. med. Bull., 8, 333. (1954). Lancet, $2,607$.

Lewis, T. (1915). Lectures on the Heart. Shaw, London.

Lian, C. (1948). Brit. Heart J., 10, 92.

Rappaport, M. B., and Sprague, H. B. (1942). Amer. Heart J., 23, 591.

Read, J. L., and Porter, W. B. (1955). Amer J. Med., 19, 177.

Reinhold, J., and Rudhe, U. (1957). Brit. Heart J., 19, 473.

Weitzman, D. (1955). Brit. Heart J., 17, 70.

Wolferth, C. C., and Margolies, A. (1935). J. clin. Invest., 14, 605. 